\title{
Modification de l'expression des métalloprotéinases de la matrice extracellulaire (MPMs) et de leur inhibiteur tissulaire (TIMP) par les fibroblastes issus de fibrose porcine sous-cutanée post-radique
}

\author{
C. LAFUMA*, R. EL NABOUT*, A. HOVNANIAN**, M. MARTIN*** \\ *Laboratoire de biologie du tissu conjonctif, URA CNRS 1460, Faculté \\ de Médecine, 94010 Créteil \\ **Laboratoire de génétique médicale, U 91 INSERM, \\ $\mathrm{CHU}$ Henri Mondor, 94010 Créteil \\ ${ }^{\star \star \star}$ Laboratoire de radiologie appliquée, CEA, DSV/DPTE, \\ 91191 Gif-sur-Yvette Cedex
}

Nous avons préalablement démontré que les fibroblastes issus de fibrose porcine sous-cutanée post-radique exprimaient, en culture primaire, une capacité de synthèse excessive du collagène, de la fibronectine et des protéoglycannes, et jouaient ainsi un rôle clé dans l'accumulation anarchique des différents composants macromoléculaires" de la matrice extracellulaire (MEC) lors de la fibrogénèse post-radique in vivo. Etant donné que ces composants sont susceptibles d'être dégradés et remodelés par des enzymes spécifiques ou métalloprotéinases de la matrice extracellulaire (MPMs), la capacité d'expression de ces MPMs fut étudiée d'une part, au niveau transcriptionnel par l'utilisation de sonde spécifique (collagénase interstitielle) et d'autre part, au niveau traductionnel par enzymographie (gélatinase/collagénase type IV/type $V$ ) et par dégradation de substrats collagène, gélatine et caséine radiomarqués.

Les résultats ont mis en évidence un affaiblissement des activités globales secrétées de la collagénase type IV/V , ainsi qu'une nette diminution de toutes les activités nettes gélatinase, collagénase interstitielle et stromélysine. Parallèlement, une disparition quasi totale des ARNm codant la collagénase interstitielle, ainsi qu'une amplification des ARNm codant le TIMP furent clairement démontrées.

L'ensemble de ces résultats nous conduit à penser que l'accumulation anarchique des composants de la MEC par les fibroblastes atypiques impliqués dans le processus de fibrogénèse post-radique est largement favorisée par la sous-expression des MPMs, associée à la surexpression de leur inhibiteur principal, le TIMP. Un tel phénotype fibrosant peut résulter d'une régulation par le TGF $B$ en excès dont on sait qu'il est émis par les fibroblastes de fibrose eux-mêmes ou par les cellules inflammatoires peuplant le tissu périfibrotique. 